\title{
Trait Emotional Intelligence Predicts Academic Satisfaction Through Career Adaptability
}

Journal of Career Assessment

$1-12$

(C) The Author(s) 2017 Reprints and permission: sagepub.com/journalsPermissions.nav DOI: $10.1177 / 10690727 / 7723290$ journals.sagepub.com/home/jca (SAGE

\author{
Pinar Celik ${ }^{1,2}$ and Martin Storme ${ }^{2}$
}

\begin{abstract}
In the current work we investigated whether trait emotional intelligence (trait El) contributes to academic satisfaction and explored a potential mechanism to explain this effect. Building on career construction theory (CCT), we hypothesized that trait El is positively associated with academic satisfaction through enhancing career-specific coping resources-the so-called career adaptabilities. Using structural equation modeling, we tested the relationship between trait El and academic satisfaction and the mediating role of career adaptability among undergraduate students $(N=$ 410). Results showed that trait El is a positive predictor of academic satisfaction and that career adaptability mediates this relationship. These results suggest that the contribution of trait El to academic satisfaction is partly due to increased perceptions of career adaptability. Theoretical and practical implications of the results are discussed.
\end{abstract}

\section{Keywords}

trait emotional intelligence, career adaptability, academic satisfaction

Studies show that students who are more satisfied with their academic life are better adjusted (Huebner \& Gilman, 2006), more optimistic (Wilkins et al., 2014), more efficient at school (Huebner \& McCullough, 2000; Verkuyten \& Thijs, 2002), and less stressed in their academic life (Chraif, 2015). Being satisfied with one's academic life is considered an important component of overall quality of life (Gilman \& Huebner, 2003; Verkuyten \& Thijs, 2002) and has been shown to contribute to future career success (Cooper, 1997; Zeidner, Matthews, \& Roberts, 2004). For career counselors, it is crucial to understand which antecedents contribute to academic satisfaction. In the current study, we focus on trait emotional intelligence (trait EI) as an antecedent of academic satisfaction and investigate a mechanism that could explain the relationship between trait EI and academic satisfaction. For career counselors, understanding the mechanism that links trait EI to academic satisfaction is invaluable because it can provide them with guidelines to shape

\footnotetext{
' Centre Emile Bernheim, Solvay Brussels School of Economics and Management, Université Libre de Bruxelles, Brussels, Belgium

${ }^{2}$ Université Paris Descartes, Boulogne-Billancourt, France
} 
interventions. A relatively straightforward mechanism to explain the relationship between trait EI and academic satisfaction involves enhanced emotion regulation skills (Extremera \& Rey, 2016; Kafetsios \& Zampetakis, 2008; Kong \& Zhao, 2013). The aim of this article is to investigate an alternate pathway that derives from career construction theory (CCT, Savickas, 2005): The role of career-specific coping resources, also referred to as career adapt-abilities (Savickas \& Porfeli, 2012). The question that we ask in the present work is whether individuals' level of career adaptability may be part of the mechanism that links trait EI to academic satisfaction.

\section{Trait El and Academic Satisfaction}

In the literature, two streams of research reflect distinct conceptualizations and measurement approaches of EI. The so-called mental ability models of emotional intelligence define EI as a set of emotion-processing skills (e.g., Mayer, Caruso, \& Salovey, 1999; Mayer \& Geher, 1996). The so-called mixed models of EI conceptualize EI as a diverse construct and adopt a trait approach to EI. These mixed models not only emphasize the ability to perceive, assimilate, understand, and manage emotions but also include aspects of personality, motivational factors, and affective dispositionssuch as self-concept, assertiveness, and empathy (Bar-On, 1997; Goleman, 1995) - as essential to EI. In the current article, we adopt the mixed models approach to EI. As such, we will use specifically the concept of trait EI in the remainder of this article.

There are several available instruments to assess trait EI, which vary in terms of the extent to which they cover the broadness of trait EI (Perera \& DiGiacomo, 2013). Because of these variations, the observed correlations between the major measures of trait EI are usually around .50 (Perera \& DiGiacomo, 2013). Perera and DiGiacomo (2013) argued that the TEI Questionnaire-Short Form (TEIQue; Petrides, 2009) covers better the construct of trait EI than other major measures such as the emotional quotient inventory (EQ-i) (Bar-On, 1997) or the Schutte Self Report Emotional Intelligence Test (SSEIT) (Schutte et al., 1998). Consequently, research using the EQ-i or the SIES has been suggested to underestimate the strength of relationships between trait EI and other constructs, compared to research using the TEIQue (Perera \& DiGiacomo, 2013).

In the current article, we use the conceptualization of Petrides and Furnham (2006), who define trait EI as a collection of affective personality characteristics and self-perceptions, related to the management of emotion-related information (i.e., perception, expression, and regulation of emotions) as well as self-control and optimistic dispositions (Perera \& DiGiacomo, 2013; Petrides \& Furnham, 2001, 2006). Specifically, Petrides and Furnham (2006) identified several components of trait EI: (1) the ability to regulate one's emotions by controlling one's urges and impulses (selfcontrol); (2) the ability to identify one's own and others' emotions and to express them accurately (emotionality); (3) the ability one has to efficiently use emotions when interacting with others in order to influence the way others feel (sociability); and (4) high self-regard and the tendency to be optimistic about one's life and past achievement (Petrides \& Furnham, 2006).

Within the framework of CCT (Savickas, 2005; Savickas \& Porfeli, 2012), trait EI could be conceptualized as essential to career-related concepts such as academic satisfaction. CCT describes the process of career and academic adaptation. The theory has arisen from the recognition of contemporary career challenges (Duffy, Douglass, \& Autin, 2015), requiring from individuals a high level of adaptation and coping resources, in order to adjust and succeed (Savickas \& Porfeli, 2012), to ultimately experience positivity in one's career, whether it is at work or at school (Maggiori, Johnston, Krings, Massoudi, \& Rossier, 2013; Wilkins et al., 2014). Perera and McIlveen (2017) distinguished four elements that are crucial in the process of career and academic adaptation. Adaptivity refers to a set of dispositional characteristics that contribute to the flexibility, readiness, and willingness to adapt. Adaptivity then is an antecedent of adaptability - which refers to the psychological resources necessary to adapt to career or academic challenges. This process is referred 
to as adapting in the CCT framework (Perera \& McIlveen, 2017). The career and academic outcomes of the whole process - such as academic achievement or academic satisfaction - are referred to as adaptation. Perera and McIlveen (2017) summarized the process of career adaptation as follows: adaptivity $\rightarrow$ adaptability $\rightarrow$ adapting $\rightarrow$ adaptation.

Huebner and Gilman (2006) have defined academic satisfaction as a subjective appraisal of the overall positivity of academic experiences. Within the framework of CCT, academic satisfaction can be seen as an outcome of career adaptation among individuals who are relatively in the beginning phase of their career. A study conducted by Sheikholeslami and Ahmadi (2011), among Iranian high school students, has shown that trait EI — as measured by the TEIQue (Petrides, 2009) — is positively associated with academic satisfaction. Another study, conducted among Iranian medicine students, also found a relation between trait EI — as measured by the EQ-i (Bar-On, 1997) — and academic satisfaction (Noughani, Bayat, Ghorbani, \& Ramim, 2015). Moreover, a variety of measures of trait EI have been shown to be significantly associated with constructs that are conceptually close to academic satisfaction, such as job and life satisfaction (Kong, Zhao, \& You, 2012; Palmer, Donaldson, \& Stough, 2002; Sy, Tram, \& O’Hara, 2006), academic achievement (Perera \& DiGiacomo, 2013), and academic stress (Miri, Kermani, Khoshbakht, \& Moodi, 2013).

CCT provides a framework to understand the relationship between trait EI and academic satisfaction. Within this framework, trait EI can be considered part of the adaptivity element of CCTthat is, the willingness and readiness to adapt to life challenges. Schneider, Lyons, and Khazon (2013), for example, showed that, when confronted with stressors, EI enhances creativity, fosters challenge appraisal rather than threat appraisal, and increases predominantly positive affect compared to negative affect. One way to understand the relation between EI and adaptivity is via the concept of resilience, which has often been linked with adaptation to life changes (Klohnen, 1996). Resilience has been found to be a predictor of the readiness and flexibility to deal with stressors in constantly changing environments (Avey, Luthans, \& Jensen, 2009). Specifically, academic resilience has been identified as a predictor of academic persistence and academic success despite environmental hardships (Cassidy, 2015). Related to trait EI, Magnano, Craparo, and Paolillo (2016) showed that the self-regulatory processes involved in EI are associated with resilience, the latter in turn supporting achievement motivation. Moreover, previous literature has also shown that trait EI is related to certain personality traits, such as openness, conscientiousness, and emotional stability (Petrides et al., 2016) that have been conceptualized as indicators of adaptivity as well (Perera \& McIlveen, 2017). Altogether, trait EI, as reflecting dispositions and self-perceptions related to affective processing and self-regulation, should contribute to the readiness and willingness to adapt to diverse challenges in life, such as career challenges. Academic satisfaction, being the result of a successful adaptation process to career challenge, should then be positively associated with trait EI. Consequently, our first hypothesis is the following:

Hypothesis 1: Trait EI is positively associated with academic satisfaction.

\section{The Mediating Role of Career Adaptability}

The specific mechanism that links trait EI to academic satisfaction has not received much attention in the literature. Research on life satisfaction emphasizes mostly general emotion regulation skills as mediating the relationship between trait EI and life satisfaction (Extremera \& Rey, 2016; Kong \& Zhao, 2013). In the same vein, Kafetsios and Zampetakis (2008) have investigated the mediating role of positive and negative affects in the relationship between trait EI and job satisfaction. However, departing from CCT, it is possible to make predictions about a career-specific psychological mechanism in the link between trait EI and academic satisfaction. Specifically, we propose that 
trait EI could be positively linked with specific career-related coping resources - that is, the adaptability element of CCT - which, in turn, could enhance academic satisfaction.

Savickas and Porfeli (2012) have identified four coping resources that contribute to career adaptability: control, concern, curiosity, and confidence. Specifically, control is the feeling of being responsible of one's future career. Concern refers to the motivation to prepare for future vocational tasks. Curiosity is the tendency to explore oneself and one's environment in order to find information that can help making future vocational decisions. Finally, confidence refers to feelings of being able to overcome future possible vocational problems.

In support of our idea of career adaptability as a mediator between trait EI and academic satisfaction, trait EI has been identified by previous research as a positive contributor when it comes to coping with career challenges. For example, Coetzee and Harry (2014) have shown that trait EIas measured by the SSEIT (Schutte et al., 1998) - predicts career adaptability among call center agents. Empirical results revealed that trait EI explained approximately $40 \%$ of the total variation of career adaptability. Coetzee and Harry (2014) argued that trait EI contributes to career adaptability because emotions play an important role when making career decisions (Brown, George-Curran, \& Smith, 2003), when, for example, discussing with others about career choices (Kidd, 1998), and also when committing to a career choice (Carson \& Carson, 1998). Moreover, career coping resources have been also shown to play an important role in students' experiences of academic satisfaction (Duffy et al., 2015). Duffy, Douglass, and Autin (2015) have shown that career adaptabilities are associated with feelings of work volition and self-efficacy regarding the decisions that students make for their careers, which in turn were associated with their academic satisfaction. Therefore, our second and third hypotheses state that trait EI positively predicts career adaptability and that career adaptability positively predicts academic satisfaction:

Hypothesis 2: Trait EI is positively associated with career adaptability.

Hypothesis 3: Career adaptability is positively associated with academic satisfaction.

Based on CCT, our final hypothesis is that trait EI predicts academic satisfaction through career adaptability. Indeed, being able to understand one's own and others' emotions, and successfully regulating one's own and others' emotions to influence others to obtain one's goals in life, should foster feelings of control, confidence, concern, and curiosity in one's academic life as well, which ultimately should lead to higher academic satisfaction:

Hypothesis 4: Career adaptability mediates the relationship between trait EI and academic satisfaction.

\section{Method}

\section{Participants}

The sample consisted of 410 third-year French (from Paris area) business administration university students $\left(M_{\text {age }}=20.77, S D_{\text {age }}=.95\right.$, ranging from from 19 to 25 years $)$. In the sample, $42 \%$ of the participants were male $(n=174)$, and $58 \%$ were female $(n=236)$. As, in France, no records of ethnic background are available to the public, we have no information about participants' ethnic background.

\section{Measurement}

Trait El (TEIQue-SF). We used the French version of the TEIQue-SF (Petrides, 2009; Mikolajczak, Luminet, Leroy, \& Roy, 2007; Petrides \& Furnham, 2001, 2006) to measure trait EI. The 
questionnaire measures four dimensions of trait EI. Well-being refers to the tendency to feel fulfilled and satisfied with life (6 items: e.g., "On the whole, I'm pleased with my life"); self-control refers to the control one has over his or her urges and impulses (6 items: e.g., "I usually find it difficult to regulate my emotions"); emotionality refers to the ability to recognize and express emotions (8 items: e.g., "Expressing my emotions with words is not a problem for me"); and sociability refers to the ability one has to use efficiently emotions when interacting with others (6 items: e.g., "I'm usually able to influence the way other people feel"). The TEIQue-SF also includes a set of items which only contributes to the global trait EI score (4 items: e.g., "Generally, I'm able to adapt to new environments"). We used 7-point Likert-type scale ranging from 1 (totally disagree) to 7 (totally agree). The TEIQue-SF has been shown to have good psychometric properties with satisfactory levels of scale score reliability (Cronbach's $\alpha$ between .59 and .95 across studies) and construct validity (Perera, 2015; Petrides, 2009; Petrides \& Furnham, 2006). In our sample, it exhibited acceptable scale score reliability (Cronbach's $\alpha$ s were, respectively, $.71, .65, .60, .63$, and .64 for well-being, self-control, emotionality, sociability, and global EI). The overall Cronbach's $\alpha$ was .85.

Career adapt-abilities (Career Adapt-Abilities Scale [CAAS]). Career adaptability was measured with the French version of the CAAS (Johnston et al., 2013; Savickas \& Porfeli, 2012). The scale assesses four dimensions of career adaptability: concern (6 items: e.g., "Concerned about my career"), control (6 items: e.g., "Making decisions by myself"), curiosity (6 items: e.g., "Probing deeply into questions I have"), and confidence (6 items: e.g., "Solving problems"). We used 5-point Likert-type scales ranging from 1 (not strong) to 5 (strongest). Previous research has shown that the original CAAS has satisfactory psychometric properties (Cronbach's $\alpha$ between .74 and .85 across subscales) and construct validity (Perera \& McIlveen, 2017; Savickas \& Porfeli, 2012). The scale showed satisfactory scale score reliability in our sample: The overall Cronbach's $\alpha$ was .92 , and Cronbach's $\alpha$ s for concern, control, curiosity, and confidence were, respectively, .81, .77, .75, and .78).

Academic satisfaction. We used a 7-item scale to measure students' satisfaction with their academic life (Lent et al., 2007). Responses were given on a 5-point Likert-type scale ranging from 1 (strongly disagree) to 5 (strongly agree). Example items are "I am generally satisfied with my academic life" and "For the most part, I am enjoying my coursework." We did not have a French translation of the academic satisfaction scale. Two French native speakers translated the 7 original items into French, and an independent English native speaker then translated them back into English for validation purposes. Previous empirical research has shown that this scale has satisfactory psychometric properties with a Cronbach's $\alpha$ of .94 and theoretically relevant correlations with academic persistence and life satisfaction (Lent et al., 2007). The scale also had satisfactory psychometric properties in our sample (Cronbach's $\alpha$ was .85).

\section{Procedure}

Students participated in this study as an extra credit opportunity. All students were enrolled in the same introductory course on human resources management. Prior to participating in the study, students received general information about the study, and the extra credit opportunity. Feedback about the main findings was provided to them at the end of the course. In order to avoid common method bias (Podsakoff, MacKenzie, Lee, \& Podsakoff, 2003), we collected the data in three phases separated by 1 week. Participants first filled in the TEIQue-SF (Petrides \& Furnham, 2006). One week after, they were asked to fill in the CAAS (Savickas \& Porfeli, 2012). Finally, another week after, they filled in the academic satisfaction scale (Lent et al., 2007). Between the first and the last data collection point, the dropout rate was $8 \%$. Questionnaires were filled in online. Anonymity and confidentiality were guaranteed by storing the responses and the student identifier in separate 
Table I. Descriptive Statistics.

\begin{tabular}{lccccccccccccc}
\hline Variable & Mean & SD & 1 & 2 & 3 & 4 & 5 & 6 & 7 & 8 & 9 & 10 & 11 \\
\hline I. Well-being (TEIQue-SF) & 4.86 & 0.76 & - & & & & & & & & & & \\
2. Self-control (TEIQue-SF) & 4.08 & 0.78 & .37 & - & & & & & & & & \\
3. Emotionality (TEIQue-SF) & 5.88 & 0.89 & .42 & .17 & - & & & & & & & \\
4. Sociability (TEIQue-SF) & 4.52 & 0.72 & .48 & .35 & .45 & - & & & & & & \\
5. Global El (TEIQue-SF) & 3.15 & 0.56 & .63 & .27 & .51 & .48 & - & & & & & \\
6. Concern (CAAS) & 3.68 & 0.66 & .43 & .22 & .17 & .27 & .43 & - & & & & \\
7. Control (CAAS) & 3.77 & 0.60 & .48 & .33 & .24 & .39 & .40 & .60 & - & & & \\
8. Curiosity (CAAS) & 3.70 & 0.57 & .29 & .19 & .17 & .25 & .28 & .55 & .59 & - & & \\
9. Confidence (CAAS) & 3.81 & 0.56 & .43 & .22 & .17 & .33 & .37 & .60 & .63 & .65 & - & & \\
10. Trait El (total) & 4.50 & 0.54 & .79 & .60 & .72 & .75 & .76 & .40 & .50 & .32 & .41 & - & \\
II. Career adaptability (total) & 3.74 & 0.50 & .49 & .29 & .23 & .37 & .45 & .83 & .84 & .83 & .85 & .49 & - \\
12. Academic satisfaction (total) & 3.50 & 0.65 & .37 & .17 & .08 & .19 & .37 & .43 & .39 & .32 & .37 & .31 & .45 \\
\hline
\end{tabular}

Note. $N=4|0| r.|>.10: p<.05 ;| r \mid>.08: p<.10$. TEIQue-SF = Trait Emotional Intelligence Questionnaire-Short Form; CAAS $=$ Career Adapt-Abilities Scale.

databases. We required that participants answered all items before they could submit their responses; consequently, we had no missing data among participants who took all the questionnaires.

\section{Analysis}

We tested our model using the framework of structural equation modeling (SEM) of Schreiber, Nora, Stage, Barlow, and King (2006) and used the R package lavaan (Rosseel, 2012) to perform the analyses. SEM is a more precise test compared to using simple sum scores because it corrects for unreliability of the measurements (Byrne, 2013). Regarding absolute model fit, we followed the recommendations of Schumacker and Lomax (2004) and used four statistical indices: The $\chi^{2} / d f$ ratio (should be less than 3 ), the comparative fit index (CFI should be more than .90), the standardized root mean square residual (SRMR should be less than .08), and the root mean square error of approximation (RMSEA should be less than .08). We report standardized model coefficients. To model academic satisfaction, we used the items of the scale as indicators. To model latent constructs of career adaptability and trait EI, we used subscale sum scores as observed indicators to be consistent with previous research on the link between EI and career adaptability (Coetzee \& Harry, 2014).

\section{Results}

Descriptive statistics are reported in Table 1. All subscales of trait EI correlated positively with career adaptabilities and academic satisfaction. However, correlations with career adaptabilities were generally stronger. One exception to this was the correlation between well-being and academic satisfaction, which was relatively strong.

For the main analyses, to begin with, we assessed the fit of the measurement model. The measurement model showed satisfactory fit $\left(\chi^{2} / d f=302.35 / 101=2.99\right.$; CFI $=.92$; SRMR $=$ .061 ; RMSEA $=.070)$. All factor loadings were significant and medium to large in magnitude. With this first analysis, we concluded that the data supported our theoretical expectations regarding the structural validity of the investigated constructs.

We then tested the hypothesized structural model. The absolute fit indices of the model were the same as those of the measurement model because our structural model was saturated. The estimates of the full model are reported in Figure 1. Our analyses revealed that the total effect of trait EI on 


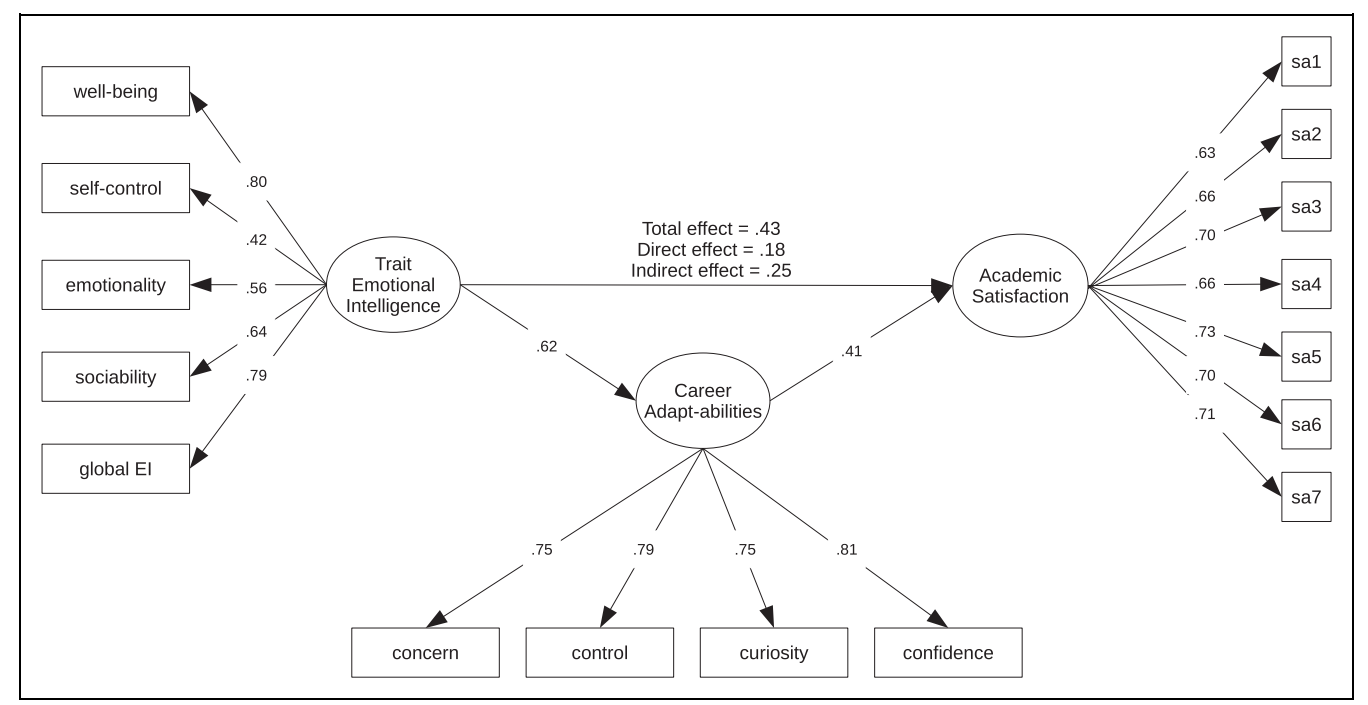

Figure I. Standardized estimates of the model (all reported estimates are significant).

academic satisfaction was positive and significant $(\beta=.43, p<.001)$. The direct effect of trait EI on academic satisfaction was still significant when controlling for career adaptability $(\beta=.18, p<.05)$ but significantly reduced $(\beta=.25, p<.001)$. This is because trait EI predicts career adaptability $(\beta=.62, p<.001)$, which predicts in turn academic satisfaction $(\beta=.41, p<.001)$. This pattern of results indicates mediation.

As recommended by Preacher, Rucker, and Hayes (2007), we computed the bootstrap interval of the indirect effect of trait EI on academic satisfaction through career adaptability to test the significance of the mediation $(\beta=.25,95 \%$ bootstrap confidence interval $(\mathrm{CI})=[.12, .39])$. Because this interval does not include 0 , we can conclude that the mediation was significant.

\section{Discussion}

The aim of the present work was to investigate the relationship between trait EI and academic satisfaction. Building on CCT (Savickas, 2005), we hypothesized that individuals with high trait EI scores would tend be more satisfied regarding their academic life and that career adaptability would mediate this relationship.

Consistent with our expectations, we found that trait EI was positively correlated with academic satisfaction. More importantly, we also found that career adaptability significantly mediated the relationship between trait EI and academic satisfaction. The indirect effect was significant, showing that career adaptability significantly reduced the effect of trait EI on academic satisfaction. These findings are consistent with our reasoning that trait EI provides individuals with resources that can help them cope with career challenges, which has in turn a positive impact on the positivity they experience in their academic life.

Our study replicates studies that established a positive link between trait EI and academic satisfaction (Noughani et al., 2015; Sheikholeslami \& Ahmadi, 2011), but also studies that showed that trait EI is an antecedent of career adaptability (Coetzee \& Harry, 2014) and that career adaptability is an antecedent of academic satisfaction (Duffy et al., 2015). Importantly, we extend these previous studies by showing that career adaptability acts as a mediator in the link between trait EI and academic satisfaction. 
Our results can be interpreted within the framework of CCT (Savickas, 2005; Savickas \& Porfeli, 2012). CCT assumes that the process of career adaptation can be described as follows: adaptivity $\rightarrow$ adaptability $\rightarrow$ adapting $\rightarrow$ adaptation (Perera \& McIlveen, 2017). We conceptualized trait EI as being part of adaptivity because previous research has shown that EI is related to several constructs reflecting the willingness and readiness to adapt, such as achievement motivation (Magnano, Craparo, \& Paolillo, 2016), academic resilience and persistence (Cassidy, 2015), adaptive stress responses (Avey et al., 2009; Schneider, Lyons, \& Khazon, 2013), and personality traits that have been described as indicators of adaptivity (Perera \& McIlveen, 2017). Given that academic satisfaction is an outcome of career adaptation, the mediating role of career adaptability in the relationship between trait EI (i.e., adaptivity) and academic satisfaction (i.e., adaptation) supports CCT.

Previous research has shown that both trait EI and career adaptability can be improved through training and coaching (Coetzee \& Harry, 2014; Di Fabio \& Kenny, 2010; Koen, Klehe, \& Van Vianen, 2012; Kotsou, Nelis, Grégoire, \& Mikolajczak, 2011). Our study suggests that trait EI training and career adaptability training can be seen as complementary approaches to increasing academic satisfaction. Indeed, one possible approach could be to improve emotion regulation strategies specifically aimed at increasing career adaptability resources. Clients, for example, could be helped in raising awareness of dysfunctional emotion management strategies, specifically to help them gain a sense of control, confidence, concern, and curiosity in overcoming any future vocational problems - which should in turn help raise feelings of academic satisfaction. In any case, future research could investigate this interesting possibility. French regional administrations in charge of university students (Centre Régional des Oeuvres Universitaires et Scolaires) increasingly acknowledge the importance of academic and life satisfaction among university students, as academic satisfaction has been found to predict important outcomes like academic achievement (Huebner \& McCullough, 2000; Verkuyten \& Thijs, 2002) and future career success (Cooper, 1997; Zeidner et al., 2004). These institutions have started, for example, implementing wellness programs for students. Such programs could benefit from our findings, as we conducted the present study specifically among French students. Specifically, students could benefit from EI training that specifically focuses on improving students' willingness to adapt, by teaching them to appraise ambiguities and difficulties in the academic context as challenges rather than threats, increasing in the process their curiosity, control, concern, and confidence (i.e., career adaptability), with the ultimate aim of building academic resilience and satisfaction.

Our study also has limitations. First, our study is based on a convenience sample of undergraduate business administration university students. Convenience samples are not necessarily detrimental to the validity of studies as noted by Highhouse and Gillespie (2009), but further research could aim at replicating our studies in other populations to investigate the generalizability of our findings. Another specificity of our sample is that it consisted of French participants. The French culture is characterized by relatively lower levels of masculinity and individualism compared to, for example, the United States (Hofstede \& Hofstede, 2011). There is evidence that masculine and collectivistic values have an impact on reported levels of job satisfaction (Kirkman, Lowe, \& Gibson, 2006). It is therefore possible that the cultural context in which our study was conducted had an impact on the results that we found. To further test the generalizability of our findings, future research could replicate our study in other cultural contexts. Finally, because our study is correlational, it is difficult to draw conclusions in terms of causality. One could reason that academic satisfaction also contributes to developing emotion management skills. Future research could therefore replicate our findings with an experimental design to test the direction of the relationship between trait EI and academic satisfaction. Implementing such a study is realistic because previous research has already tested the possibility of manipulating trait EI with appropriate training modules (Kotsou et al., 2011). 
To conclude, our study showed that trait EI is a positive predictor of academic satisfaction and that this relationship can be partially explained by the mediating role of resources helping to cope with career challenges. Academic satisfaction is an important outcome for vocational counselors because it contributes to overall quality of life (Gilman \& Huebner, 2003), school adjustment, optimism, academic commitment but also to academic and future career performance (Huebner \& Gilman, 2006; Huebner \& McCullough, 2000; Verkuyten \& Thijs, 2002; Wilkins et al., 2014). Our finding that trait EI is an antecedent of academic satisfaction through career adaptability could be valuable to career counselors who wish to tailor their vocational interventions to their clients' characteristics.

\section{Declaration of Conflicting Interests}

The author(s) declared no potential conflict of interest with respect to the research, authorship, and/or publication of this article.

\section{Funding}

The author(s) received no financial support for the research, authorship, and/or publication of this article.

\section{References}

Avey, J. B., Luthans, F., \& Jensen, S. M. (2009). Psychological capital: A positive resource for combating employee stress and turnover. Human Resource Management, 48, 677-693. doi:10.1002/hrm.20294

Bar-On, R. (1997). The emotional quotient inventory (eQ-i): Technical manual. Toronto, Canada: Multi-Health Systems.

Brown, C., George-Curran, R., \& Smith, M. L. (2003). The role of emotional intelligence in the career commitment and decision-making process. Journal of Career Assessment, 11, 379-392. doi:10.1177/ 1069072703255834

Byrne, B. M. (2013). Structural equation modeling with IISREL, pRELIS, and sIMPLIS: Basic concepts, applications, and programming. New York, NY: Psychology Press.

Carson, K. D., \& Carson, P. P. (1998). Career commitment, competencies, and citizenship. Journal of Career Assessment, 6, 195-208. doi:10.1177/106907279800600206

Cassidy, S. (2015). Resilience building in students: The role of academic self-efficacy. Frontiers in Psychology, 6. doi:10.3389/fpsyg.2015.01781

Chraif, M. (2015). Correlative study between academic satisfaction, workload and level of academic stress at 3rd grade students at psychology. Procedia—Social and Behavioral Sciences, 203, 419-424. doi:10.1016/j. sbspro.2015.08.317

Coetzee, M., \& Harry, N. (2014). Emotional intelligence as a predictor of employees' career adaptability. Journal of Vocational Behavior, 84, 90-97. doi:10.1016/j.jvb.2013.09.001

Cooper, R. K. (1997). Applying emotional intelligence in the workplace. Training \& Development, 51, 31-39.

Di Fabio, A., \& Kenny, M. E. (2010). Promoting emotional intelligence and career decision making among Italian high school students. Journal of Career Assessment, 19, 21-34. doi:10.1177/1069072710382530

Duffy, R. D., Douglass, R. P., \& Autin, K. L. (2015). Career adaptability and academic satisfaction: Examining work volition and self efficacy as mediators. Journal of Vocational Behavior, 90, 46-54. doi:10.1016/j.jvb. 2015.07.007

Extremera, N., \& Rey, L. (2016). Ability emotional intelligence and life satisfaction: Positive and negative affect as mediators. Personality and Individual Differences, 102, 98-101. doi:10.1016/j.paid.2016.06.051

Gilman, R., \& Huebner, S. (2003). A review of life satisfaction research with children and adolescents. School Psychology Quarterly, 18, 192-205. doi:10.1521/scpq.18.2.192.21858

Goleman, D. (1995). Emotional intelligence. New York, NY: Bantam Books. 
Highhouse, S., \& Gillespie, J. Z. (2009). Do samples really matter that much? In C. E. Lance \& R. J. Vandenberg (Eds.), Statistical and methodological myths and urban legends: Doctrine, verity and fable in the organizational and social sciences (pp. 247-265). New York, NY: Routledge.

Hofstede, G. H., \& Hofstede, G. (2001). Culture's consequences: Comparing values, behaviors, institutions and organizations across nations. Thousand Oaks, CA: Sage.

Huebner, E. S., \& Gilman, R. (2006). Students who like and dislike school. Applied Research in Quality of Life, 1, 139-150. doi:10.1007/s11482-006-9001-3

Huebner, E. S., \& McCullough, G. (2000). Correlates of school satisfaction among adolescents. The Journal of Educational Research, 93, 331-335. doi:10.1080/00220670009598725

Johnston, C. S., Broonen, J.-P., Stauffer, S. D., Hamtiaux, A., Pouyaud, J., Zecca, G., . . Rossier, J. (2013). Validation of an adapted French form of the career adapt-abilities scale in four francophone countries. Journal of Vocational Behavior, 83, 1-10. doi:10.1016/j.jvb.2013.02.002

Kafetsios, K., \& Zampetakis, L. A. (2008). Emotional intelligence and job satisfaction: Testing the mediatory role of positive and negative affect at work. Personality and Individual Differences, 44, 712-722. doi:10. 1016/j.paid.2007.10.004

Kidd, J. M. (1998). Emotion: An absent presence in career theory. Journal of Vocational Behavior, 52, 275-288. doi:10.1006/jvbe.1997.1629

Kirkman, B. L., Lowe, K. B., \& Gibson, C. B. (2006). A quarter century of culture's consequences: A review of empirical research incorporating Hofstede's cultural values framework. Journal of International Business Studies, 37, 285-320. doi:10.1057/palgrave.jibs. 8400202

Klohnen, E. C. (1996). Conceptual analysis and measurement of the construct of ego-resiliency. Journal of Personality and Social Psychology, 70, 1067. doi:10.1037/0022-3514.70.5.1067

Koen, J., Klehe, U.-C., \& Van Vianen, A. E. (2012). Training career adaptability to facilitate a successful school-to-work transition. Journal of Vocational Behavior, 81, 395-408. doi:10.1016/j.jvb.2012.10.003

Kong, F., \& Zhao, J. (2013). Affective mediators of the relationship between trait emotional intelligence and life satisfaction in young adults. Personality and Individual Differences, 54, 197-201. doi:10.1016/j.paid.2012.08.028

Kong, F., Zhao, J., \& You, X. (2012). Emotional intelligence and life satisfaction in Chinese university students: The mediating role of self-esteem and social support. Personality and Individual Differences, 53, 1039-1043. doi:10.1016/j.paid.2012.07.032

Kotsou, I., Nelis, D., Grégoire, J., \& Mikolajczak, M. (2011). Emotional plasticity: Conditions and effects of improving emotional competence in adulthood. Journal of Applied Psychology, 96, 827. doi:10.1037/a0023047

Lent, R. W., Singley, D., Sheu, H.-B., Schmidt, J. A., \& Schmidt, L. C. (2007). Relation of social-cognitive factors to academic satisfaction in engineering students. Journal of Career Assessment, 15, 87-97. doi:10. $1177 / 1069072706294518$

Maggiori, C., Johnston, C. S., Krings, F., Massoudi, K., \& Rossier, J. (2013). The role of career adaptability and work conditions on general and professional well-being. Journal of Vocational Behavior, 83, 437-449. doi: 10.1016/j.jvb.2013.07.001

Magnano, P., Craparo, G., \& Paolillo, A. (2016). Resilience and emotional intelligence: Which role in achievement motivation. International Journal of Psychological Research, 9, 9-20.

Mayer, J. D., Caruso, D. R., \& Salovey, P. (1999). Emotional intelligence meets traditional standards for an intelligence. Intelligence, 27, 267-298. doi:10.1016/S0160-2896(99)00016 -1

Mayer, J. D., \& Geher, G. (1996). Emotional intelligence and the identification of emotion. Intelligence, 22, 89-113. doi:10.1016/S0160-2896(96)90011-2

Mikolajczak, M., Luminet, O., Leroy, C., \& Roy, E. (2007). Psychometric properties of the trait emotional intelligence questionnaire: Factor structure, reliability, construct, and incremental validity in a Frenchspeaking population. Journal of Personality Assessment, 88, 338-353. doi:10.1080/00223890701333431

Miri, M. R., Kermani, T., Khoshbakht, H., \& Moodi, M. (2013). The relationship between emotional intelligence and academic stress in students of medical sciences. Journal of Education and Health Promotion, 2, 40. doi:10.4103/2277-9531.115836 
Noughani, F., Bayat, R. M., Ghorbani, Z., \& Ramim, T. (2015). Correlation between emotional intelligence and educational consent of students of Tehran University of Medical Students. Teheran University Medical Journal, 73, 110-116.

Palmer, B., Donaldson, C., \& Stough, C. (2002). Emotional intelligence and life satisfaction. Personality and Individual Differences, 33, 1091-1100. doi:10.1016/S0191-8869(01)00215-X

Perera, H. N. (2015). The internal structure of responses to the trait emotional intelligence questionnaire-Short form: An exploratory structural equation modeling approach. Journal of Personality Assessment, 97, 411-423. doi:10.1080/00223891.2015.1014042

Perera, H. N., \& DiGiacomo, M. (2013). The relationship of trait emotional intelligence with academic performance: A meta-analytic review. Learning and Individual Differences, 28, 20-33. doi:10.1016/j.lindif.2013.08.002

Perera, H. N., \& McIlveen, P. (2017). Profiles of career adaptivity and their relations with adaptability, adapting, and adaptation. Journal of Vocational Behavior, 98, 70-84. doi:10.1080/00223891.2015. 1014042

Petrides, K. V. (2009). Psychometric properties of the trait emotional intelligence questionnaire (tEIQue). In A. J. D. Parker, H. D. Saklofske, \& C. Stough (Eds.), Assessing emotional intelligence: Theory, research, and applications (pp. 85-101). Boston, MA: Springer US. doi:10.1007/978-0-387-88370-05

Petrides, K. V., \& Furnham, A. (2001). Trait emotional intelligence: Psychometric investigation with reference to established trait taxonomies. European Journal of Personality, 15, 425-448. doi:10.1002/per.416

Petrides, K. V., \& Furnham, A. (2006). The role of trait emotional intelligence in a gender-specific model of organizational variables. Journal of Applied Social Psychology, 36, 552-569. doi:10.1111/j.0021-9029. 2006.00019.x

Petrides, K. V., Mikolajczak, M., Mavroveli, S., Sanchez-Ruiz, M.-J., Furnham, A., \& Pérez-González, J.-C. (2016). Developments in trait emotional intelligence research. Emotion Review, 8, 335-341. doi:10.1177/ 1754073916650493

Podsakoff, P. M., MacKenzie, S. B., Lee, J.-Y., \& Podsakoff, N. P. (2003). Common method biases in behavioral research: A critical review of the literature and recommended remedies. Journal of Applied Psychology, 88, 879-903. doi:10.1037/0021-9010.88.5.879

Preacher, K. J., Rucker, D. D., \& Hayes, A. F. (2007). Addressing moderated mediation hypotheses: Theory, methods, and prescriptions. Multivariate Behavioral Research, 42, 185-227. doi:10.1080/ 00273170701341316

Rosseel, Y. (2012). Lavaan: An r package for structural equation modeling. Journal of Statistical Software, 48, 1-36. doi:10.18637/jss.v048.i02

Savickas, M. L. (2005). The theory and practice of career construction. In S. D. Brown \& R. W. Lent (Eds.), Career development and counseling: Putting theory and research to work (pp. 42-70). New York, NY: John Wiley.

Savickas, M. L., \& Porfeli, E. J. (2012). Career adapt-abilities scale: Construction, reliability, and measurement equivalence across 13 countries. Journal of Vocational Behavior, 80, 661-673. doi:10.1016/j.jvb. 2012.01.011

Schneider, T. R., Lyons, J. B., \& Khazon, S. (2013). Emotional intelligence and resilience. Personality and Individual Differences, 55, 909-914. doi:10.1016/j.paid.2013.07.460

Schreiber, J. B., Nora, A., Stage, F. K., Barlow, E. A., \& King, J. (2006). Reporting structural equation modeling and confirmatory factor analysis results: A review. The Journal of Educational Research, 99, 323-338.

Schumacker, R. E., \& Lomax, R. G. (2004). A beginner's guide to structural equation modeling. New York, NY: Psychology Press.

Schutte, N. S., Malouff, J. M., Hall, L. E., Haggerty, D. J., Cooper, J. T., Golden, C. J., \& Dornheim, L. (1998). Development and validation of a measure of emotional intelligence. Personality and Individual Differences, 25, 167-177. 
Sheikholeslami, R., \& Ahmadi, S. (2011). The relationship between emotional intelligence and academic satisfaction in students. International Journal of Behavioral Sciences, 5, 135-142.

Sy, T., Tram, S., \& O'Hara, L. A. (2006). Relation of employee and manager emotional intelligence to job satisfaction and performance. Journal of Vocational Behavior, 68, 461-473. doi:10.1016/j.jvb.2005.10.003

Verkuyten, M., \& Thijs, J. (2002). School satisfaction of elementary school children: The role of performance, peer relations, ethnicity and gender. Social Indicators Research, 59, 203-228. doi:10.1023/A: 1016279602893

Wilkins, K. G., Santilli, S., Ferrari, L., Nota, L., Tracey, T. J., \& Soresi, S. (2014). The relationship among positive emotional dispositions, career adaptability, and satisfaction in Italian high school students. Journal of Vocational Behavior, 85, 329-338. doi:10.1016/j.jvb.2014.08.004

Zeidner, M., Matthews, G., \& Roberts, R. D. (2004). Emotional intelligence in the workplace: A critical review. Applied Psychology, 53, 371-399. doi:10.1111/j.1464-0597.2004.00176.x 